\title{
Symmetric and Asymmetric Causal Relationship between Oil Prices and G7 Stock Markets: A Bootstrap Rolling-Window Granger Causality Test
}

\author{
Khaled Mokni ${ }^{1,2+}$, Mohamed Sahbi Nakhli ${ }^{3,4}$, Othman Mnari3,4, and Khemaies Bougatef ${ }^{3}$ \\ ${ }^{1}$ Northern Border University, Saudi Arabia \\ ${ }^{2}$ Gabès University, Tunisia \\ ${ }^{3}$ University of Kairouan, Tunisia \\ ${ }^{4}$ University of Sousse, Tunisia
}

\begin{abstract}
This study examines the causal relationships between oil prices and the MSCI stock index of G7 countries between September 2004 and October 2020. This study is novel in implementing symmetric and asymmetric time-varying causality tests based on the bootstrap rolling-window approach. The results reveal that the causal link between oil prices and G7 stock markets is time-dependent. The periods of bidirectional causality roughly coincide with the global financial crisis and the ongoing COVID-19 pandemic. When asymmetry is accounted for, the results suggest an asymmetric causality between the two markets expressed by different patterns regarding positive and negative oil shocks. The results also indicate symmetric causality during the COVID-19 pandemic. These findings have implications for portfolio design and hedging strategies that are important to both policymakers and investors.
\end{abstract}

Keywords: oil price, stock market, G7 country, time-varying causality, asymmetry

JEL Classifications: G10, Q43

Received 14 May 2021, Revised 25 August 2021, Accepted 30 August 2021

\section{Introduction}

The dependence of economies on oil, especially in developed countries, has increased substantially since the oil shocks of the 1970s. Oil prices have drawn much attention from investors, policymakers, and academics amid the increased demand for oil as well as intensifying

\footnotetext{
+Corresponding Author: Khaled Mokni

Assistant professor, College of Business Administration, Northern Border University, Arar 91431, Saudi Arabia / Institut Supérieur de Gestion de Gabès, Gabès University, Gabès 6002, Tunisia. Email: kmokni@gmail.com

Co-Author: Mohamed Sahbi Nakhli

Assistant professor, ISIG Kairouan, University of Kairouan, Tunisia / LaREMFIQ Laboratory, University of Sousse, Tunisia. Email: sahbinakhli@yahoo.fr

Co-Author: Othman Mnari

Assistant professor, ISIG Kairouan, University of Kairouan, Tunisia/LaREMFIQ Laboratory, University of Sousse, Tunisia. Email: mnaritn@gmail.com
}

Co-Author: Khemaies Bougatef

Associate professor, ISIG Kairouan, University of Kairouan, Tunisia. Email: khemaies_bougatef@yahoo.fr 
economic development and commodity financialization. Oil prices have become one of the most interesting economic and financial indicators, and an increasing number of studies appear on oil price dynamics in the context of the macroeconomy (Chen et al., 2019; Hamilton, 1983, 2003; Hooker, 1996; Kilian \& Vigfusson, 2013; Mork, 1989), social queries (Musgrove, 1981; Kocaaslan, 2019; Naranpanawa \& Bandara, 2012; Uri, 1996), and financial markets (Basher \& Sadorsky, 2006; Chen et al., 1986; Jones \& Kaul, 1996; Kilian \& Park, 2009; Mokni, 2020a, b; Sadorsky, 1999; Youssef \& Mokni, 2019). Therefore, investigating the relationship between oil prices and financial markets is crucial to investors and policymakers.

The last two decades have witnessed the increased financialization of commodities and various crises in global financial markets. Thus, investigating the relationship between oil price behavior and stock markets is important for both scholars and policymakers for several reasons. On the one hand, oil is considered a major input to many economic activities (Herrera et al., 2019). On the other hand, stock markets play a crucial role in boosting economic growth (Fufa \& Kim, 2018). According to Waheed et al. (2018), oil price change is one of the most influential underlying forces in the stock market. Indeed, the global crude oil market is an integral component and is intimately intertwined with other markets, like the equity market (Xiao \& Wang, 2020). Numerous researchers have analyzed this interrelationship. However, the results of these studies have been mixed: Some studies find a negative association between oil price changes and stock market returns (Jiménez-Rodriguez, 2014), while others find a positive linkage (Zhu et al., 2014; Youssef \& Mokni, 2019).

Theoretically speaking, the oil price-stock markets relationship is strongly related to several potential transmission channels (Degiannakis et al., 2018). The first one is related to investors' stock valuation task, whereby oil price fluctuations may be transmitted to firms via the expected cash flows. An increase in oil prices can be interpreted as good news by investors, who expect more cash flows, leading to stock market appreciation. By contrast, a drop in oil price will negatively affect firms' future cash flows, leading to stock market depreciation.1) The second channel is related to the aggregate demand; oil price fluctuations influence consumption and affect the company's profile and stocks. The third transmission channel is attributed to monetary policy. Increases in oil prices lead to higher inflation. The resultant increase in interest rates will increase borrowing costs for firms and thus lower predicted cash flows, leading to a drop in the stock market. Finally, the production cost is a theoretical channel through which oil prices can be linked to stock markets. An upsurge in oil price represents a supplementary production cost; this affects firms' production costs and expected cash flows, which then negatively affects stock markets.

This study investigates the time-varying causal relationships between oil prices and G7

1) Regarding this issue, several studies, including Nandha and Faff (2008) and Mokni (2020a, b), claim that the reaction of stock markets to oil prices depends on whether the firm belongs to a net oil-producer industry or a net oil-consumer industry. 
countries' stock markets using symmetric and asymmetric time-varying causality tests based on the bootstrap rolling-window approach. We focus on G7 countries because they are the seven most advanced economies in the world, and their economic systems exhibit remarkable differences in terms of policy interventions, economic reforms, and financial regulation activities (Bastianin et al., 2016).

While some researchers emphasize the equity market's symmetric response to changes in oil prices, others find differences in impact between negative and positive oil price shocks (Mokni, 2020b; Xiao \& Wang, 2020). Recently, several authors analyzed the behavior of the oil-stock nexus during the COVID-19 outbreak. Liu et al. (2020b) report a negative connection between crude oil returns and US stock market returns during the COVID-19 pandemic. Prabheesh et al. (2020a) report a positive co-movement between oil prices and stock price returns during the pandemic for a sample of oil-importing Asian countries. Salisu et al. (2020) find that stock markets may have experienced a greater initial and prolonged impact of oil shocks during the pandemic than they did in the period before it.

Overall, the literature provides divergent results concerning the sign and strength of this relationship: Some studies point to a positive relationship, whereas others find a negative one. However, the more recent literature reports that the sign and strength of oil price-stock market nexus depends on the market condition and analysis period (Mokni, 2020a, b). This divergence in results may be related to the methodologies used, specifically whether they assume that the oil price-stock market relationship is symmetric and constant over time. Several recent studies, including Kang et al. (2015) and Mokni (2020a, b), have used sophisticated methodologies to find that this relationship is not constant but changes over time.

On the other hand, abundant literature on the oil-stock nexus using causality analysis provides fruitful findings that offer valuable information for oil and stock market investors, who seek to avoid severe stock market disruptions caused by oil price shocks, especially during periods of economic turbulence. In a similar vein, our study employs the bootstrap Granger causality test and rolling estimation to examine the time-varying dependence between crude oil shocks and G7 stock market returns during periods of economic turbulence such as the global financial crisis of 2008, the crude oil crises of 2008-2009, the oil price collapse of 2014-2015, and the COVID-19 pandemic. The main advantage of applying the time-varying causality test is its ability to identify periods where the causal correlations between oil and equity are more severe and determine whether these causality changes coincide with times of economic depression and financial instability.

This study adds to the debate on the oil-stock nexus in several ways. First, our study investigates the oil price-stock market relationship in G7 countries using a time-varying causality test that has the advantage of localizing periods of causality over time. Second, unlike previous studies that focus on the causality between these two markets, our study analyzes the sign 
of the causality, which offers a more comprehensive picture of the relationship. Third, this study analyses the causal relationship between oil prices and G7 stock market returns in an asymmetric framework. This analysis identifies the causality from positive and negative returns to detect a possible asymmetric causal link between the two markets. Several studies have confirmed the asymmetric behavior in the response of stock markets to oil price changes. This asymmetry between the two markets may be due to the presence of market power (Scherer \& Ross, 1990), changes in policies related to commodity markets (Rapsomanikis et al., 2003), and investors' tendency to react more strongly to adverse than to favorable changes in financial markets (Hatemi-J, 2012; Hatemi-J et al., 2017). Finally, this study considers a timely sample period, defined by the ongoing health crisis caused by the COVID-19 pandemic.

The results of this study indicate that the relationship between West Texas Intermediate (WTI) oil prices and the Morgan Stanley Capital International (MSCI) G7 stock market is time-varying. We find a bidirectional causality generally coincides with stress periods, including the global financial crisis, the European debt crisis, and the ongoing COVID-19 pandemic. We conduct further analysis accounting for the asymmetry in oil price and MSCI G7 stock index changes by decomposing the oil price and stock index returns into positive and negative shocks. Applying the same test while separating positive from negative shocks, we find that the causality running from oil prices to the G7 stock markets is asymmetric, expressed by different patterns of positive and negative oil shocks. Moreover, similar results are found for the asymmetric causality running from stock returns to oil prices. The results also suggest symmetric causality over the course of the COVID-19 pandemic.

The remainder of this paper is structured as follows. Section 2 presents an overview of studies on the relationship between oil price changes and stock returns. Section 3 describes the study's data and empirical methodology. The results are presented and discussed in Section 4. Finally, Section 5 concludes the paper and offers policy recommendations.

\section{Literature Review}

A large body of research has found connections between oil prices and stock markets. However, no consensus about the nature of this relationship has been reached. Jiménez-Rodriguez (2014) tests the non-linearity between oil prices and stock returns, finding a negative response of real stock returns to oil price shocks for the United States (US), Canada, Germany, and the United Kingdom (UK). O'Neill et al. (2008) point out that oil price increases affect stock market returns differently across countries: While oil price increases are found to be negatively associated with stock market returns in the US, the UK, and France, their effects on stock market performance are positive in Canada and Australia. Driesprong et al. 
(2008) find that higher oil prices drastically lower future stock returns in developed and emerging markets. Similarly, Park and Ratti (2008) show that an increase in oil price volatility significantly depresses real stock returns for 12 European countries. A negative relationship between oil price behavior and stock market returns is reported in numerous studies, such as Miller and Ratti (2009) for six OECD countries, Papapetrou (2001) for Greece, and Huang et al. (2005), and Huang and Guo (2008) for Japan.

By contrast, other studies find a positive association between oil price increases and stock market returns. Zhu et al. (2014) show a positive linkage between crude oil prices and stock market returns in nine countries across the Asia-Pacific region before the global financial crisis and find that it intensified considerably in the aftermath of the crisis. Lee et al. (2012) find that short-term stock price movements lead to positive oil price movements. Cong et al. (2008) show that the stock returns of the manufacturing index and several oil companies increased due to oil price shocks in China. A positive interaction between oil price changes and sector stock price changes is found by Narayan and Narayan (2010) for Vietnam and O'Neill et al. (2008) for Canada and Australia.

These findings may be contradictory because the nature of the relationship between oil price changes and stock market return changes depending on whether a country is an oil importer or an oil exporter (Cong et al., 2008; Creti et al., 2014; O’Neill et al., 2008; Park \& Ratti, 2008; Youssef \& Mokni, 2019). While this relationship tends to be negative for oil-importing countries, it is expected to be positive for oil-exporting ones because increased oil prices offer them added revenue (Jammazi et al., 2017). The reaction of stock returns to an oil price shock also depends on the source of the underlying cause of the oil price change (Abhyankar et al., 2013; Kilian \& Park, 2009). On the other hand, Arouri and Nguyen (2010) and Huang et al. (2015) point that the stock return reactions to changes in oil prices vary significantly depending on the activity sector. Phan et al. (2015) find that fluctuations in oil prices positively impact stock market returns for the oil producer sector but have a negative impact on the oil consumer sector.

While the aforementioned studies assess the interlinkage between oil price changes and stock market returns over the whole sample period, recent research focuses more on multiscale settings, finding that the relationship between oil prices and stock returns is not homogenous on all scales over time. Reboredo and Rivera-Castro (2014) apply the wavelet multi-resolution method to analyze the interaction between oil and stock prices in Europe and the US at the aggregate and sectoral levels over the global financial crisis period. For the pre-crisis period, the results show that oil price fluctuations have no impact on stock returns at either the aggregate or sectoral level, except for oil and gas company stocks. The findings also reveal contagion and positive interdependence between oil prices and stocks at all time scales since July 2008 at both global and sectoral levels. Baruník et al. (2016) employ the wavelet approach to analyze 
the dynamic correlation between oil and stocks in the US. Their findings confirm an oil-stocks dependence since the onset of the global financial crisis. Moreover, a dramatic increase in the oil-stock correlation during the post-subprime financial crisis period is found. Using wavelet and copula methodology, Jammazi and Reboredo (2016) also confirm oil-stock dependencies, especially in the aftermath of the financial crisis. Jammazi et al. (2017) combine wavelet and Granger causality tests to explore the existence of causal linkages in mean and variance between oil prices and stocks for France, Germany, Italy, Spain, the UK, and the US, the world's six largest oil importers. Bidirectional causal links between oil price changes and stock returns are found for all countries. The causal links appear to be stronger at coarser scales and during global financial and European debt crises. In a more recent study, Mokni (2020b) also confirms an increase in the relationship between variables during the global financial crisis in most oil-exporting and -importing countries. Çevik et al. (2018) find a significant causal relationship between oil prices and MSCI G7 stock returns during and after the global financial crisis.

Cheema and Scrimgeour (2019) focus on oil and stock market anomalies, ${ }^{2}$ ) concluding that the anomalies are greater following increases in oil prices than following decreases and that the anomalies are greater when the increase in oil price is attributable to higher oil demand. A large body of literature also examines the effect of structural oil price shocks on stock market returns. Mokni (2020a) uses a structural VAR model and a time-varying parameter regression model to analyze the response of stock market returns to oil price shocks for oil-exporting and -importing countries from 1999 to 2018, while distinguishing between supply shocks, aggregate demand shocks, and oil-specific demand shocks among global oil price shocks. The results show a time-varying response of all financial markets to the shocks. He also suggests that the incidence of supply shocks on market returns is minimal and negative; however, the aggregate demand shocks positively impact stock markets for the whole sample. Moreover, oil-specific demand shocks are found to negatively impact oil-importing countries, except for the Chinese stock market, and positively impact oil-exporting countries. Other researchers seek to identify the origins of oil price shocks when analyzing their impact on stock market returns. They indicate that a rise in oil prices related to an oil demand shock is interpreted as positive news in financial markets (Basher et al., 2012; Kang et al., 2015; Kilian \& Park, 2009). However, Cunado and De Gracia (2014) and Cashin et al. (2014) show that a rise in oil prices related to an oil supply shock leads to a negative interaction between oil prices and stock market returns. Kilian (2009), Kilian and Park (2009), Güntner (2014), Zhu et al. (2016), and Basher et al. (2018) suggest that oil demand shocks have a greater effect on stock returns than oil supply shocks do.

Kang et al. (2015) use the time-varying parameter VAR model to examine the effect of structural oil price shocks on stock market returns and show that the interaction between oil price shocks and stock returns is not stable over time. Both Tchatoka et al. (2018) and Bouoiyour

2) See Cheema and Scrimgeour (2019) for more information about anomalies. 
et al. (2017) apply quantile-on-quantile (QQ) regression and find heterogeneity in the interaction between oil price shocks and stock market returns. Mokni (2020b) uses a time-varying asymmetric quantile regression (TV-QAR) approach to study the largest oil-exporting and -importing countries to show that the oil-stock nexus is time-varying. Zhu et al. (2016) and Bouoiyour et al. (2017) suggest that stock returns are more responsive to oil shocks in oil-exporting countries than oil-importing countries. Lee et al. (2020) apply a Granger causality in quantiles approach and show a strong bi-directional causality between oil prices and the green bond index for lower quantiles in the US. Balcilar et al. (2020) report that oil uncertainty increases US bond returns and volatility.

Another research stream discusses the asymmetric effect of oil price changes on stock market returns. Jiménez-Rodríguez (2014) shows that a rise in oil prices has a greater impact on MSCI stock market returns than a decline has. Narayan and Gupta (2015) find that positive/negative variations in oil prices significantly predict US stock returns but that negative variations are more relevant. Ramos and Veiga (2013) report asymmetric impacts only in oil-importing countries, not in oil-exporting ones. Mokni (2020b) shows asymmetric effects between oil and stock markets and finds that oil-importing countries' stock returns react more strongly to negative variations in oil prices than positive variations. Phan et al. (2015) find an asymmetric impact of oil price variations on stock returns in the oil consumer sector but not in the oil producer sector. Many other researchers conclude that oil price changes have asymmetric effects on stock market returns (Badeeb \& Lean, 2018; Basher \& Sadorsky, 2006; Hatemi-J et al., 2017; Sadorsky, 1999; Salisu \& Oloko, 2015). By contrast, other studies find no evidence that oil price changes have asymmetric impacts on stock market returns (Asalman \& Herrera, 2015; Cong et al., 2008).

Recently, many studies have analyzed the importance of oil price dynamics and the influence of the COVID-19 pandemic on the global economy. According to McKibbin and Fernando (2020), COVID-19 negatively affects the world economy, particularly in terms of commodity prices, GDP, and stock markets. Zhang et al. (2020) analyze the impact of the COVID-19 pandemic on stock market risk in global financial markets, finding that their risks have grown significantly in response to the COVID-19 pandemic. Liu et al. (2020a) indicate that the pandemic has had a considerably negative impact on stock market returns in the most affected countries. Lee et al. (2021) use a structural VAR framework to examine the dynamic connection between macroeconomic fluctuations and hospitality stock returns during the COVID-19 pandemic in China and report that pandemic-related shocks have had a substantial impact on macroeconomic fluctuations and hospitality stock returns. Other studies, including Štifanić et al. (2020), Sharif et al. (2020), and Zhang and Hamori (2021), investigate the effect of oil price changes on stock markets. Štifanić et al. (2020) examine the impact of COVID-19 on crude oil price changes and three US stock indexes: DJI, S\&P 500, and NASDAQ Composite. 
They argue that the COVID-19 outbreak has had a huge impact on crude oil prices and stock markets. Shaikh (2021) finds that global crude oil prices have tended to be more volatile during the COVID-19 pandemic. Sharif et al. (2020) use the coherence wavelet approach and wavelet-based Granger causality tests to examine the effects of COVID-19 on oil price volatility, stock markets, geopolitical risk, and economic policy uncertainty in the US, finding that the COVID-19 pandemic has had the greatest impacts on US economic uncertainty and US geopolitical risk; they also find that the drop in oil prices had a substantial impact on US stock markets. Zhang and Hamori (2021) examine the dependence between the crude oil market and stock markets during the COVID-19 pandemic in the US, Japan, and Germany. They conclude that the COVID-19 crisis has had a greater influence on oil price and stock market volatility than the 2008 global financial crisis had.

\section{Data and methodology}

\section{A. Data}

This study uses monthly data covering September 2004 to October 2020 to examine the time-varying Granger causality between G7 countries' stock market index and oil price. We use the MSCI stock index in US dollars for the G7 countries (i.e., Canada, France, Germany, Italy, Japan, the UK, and the US). In addition, we use the WTI price as a proxy for oil prices. All the data are collected from DataStream.

The evolution of the two key variables is reported in Fig. 1. The figure shows a somewhat similar evolution, especially in the beginning and middle of the study period. The stock index and WTI oil price were relatively stable between 2004 and 2007, followed by a reverse evolution during the global financial crisis, as reflected by an increase in the oil price and a decrease in the MSCI G7 stock index. From 2014, the oil price decreased steeply following the so-called "oil price collapse," whereas the stock index shows an increasing trend. 
Figure 1. Monthly Crude MSCI G7 Stock Market Index and Oil Price
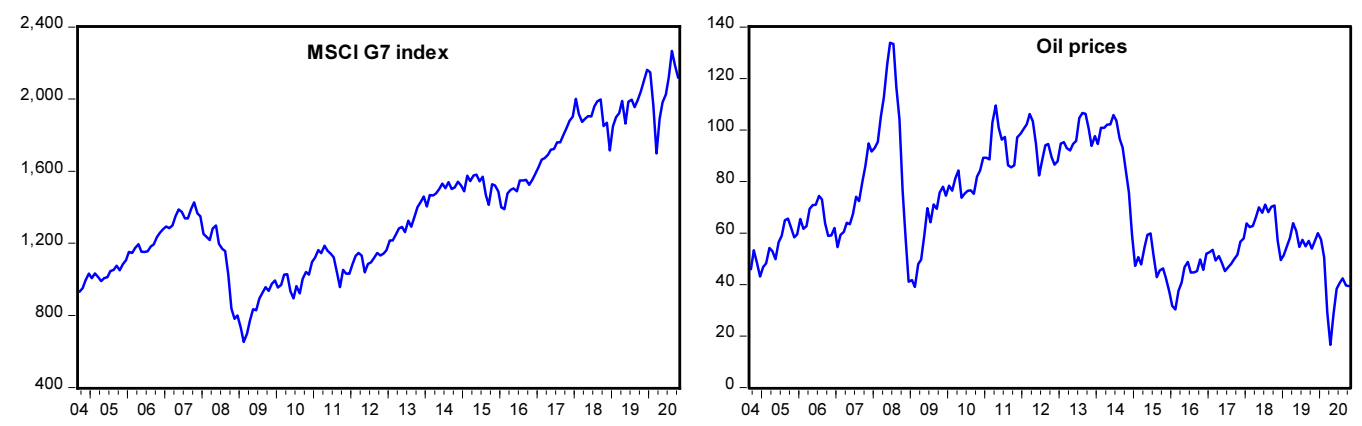

Our empirical research is based on returns instead of price series. The return series are computed as the percentage of log-difference, following the formula $R_{t}=100 \times \log \left(P_{t} / P_{t-1}\right)$, where $P_{t}$ reflects the oil or stock prices in month t. Figure 2 presents the return fluctuations of the two series. We observe high variations in oil and stock returns, expressed by volatility clustering. Moreover, the oil and MSCI G7 returns exhibit more fluctuations over the period of turmoil (i.e., the global financial crisis), European debt crisis, the last oil price collapse, and, even more intensively, during the ongoing COVID-19 pandemic.

We investigate the causality between oil prices and G7 stock returns in an asymmetric framework by decomposing each return series into positive and negative changes (e.g., Gaies et al., 2021; Nakhli \& Gaies, 2021; Shin et al., 2014). The positive and negative oil price changes are defined, respectively, by $\operatorname{Oil}_{t}^{+}=\max \left(O i l_{i}, 0\right)$ and $O i l_{t}^{-}=\min \left(O i l_{i}, 0\right)$, where $\mathrm{Oil}_{t}$ denotes the WTI returns at month $t$. Similarly, we define the positive and negative changes in the MSCI G7 stock price as $G 7_{t}^{+}=\max \left(G 7_{i}, 0\right)$ and $G 7_{t}^{-}=\min \left(G 7_{i}, 0\right)$, where $G 7_{t}$ denotes the stock returns at month $t$.

Figure 2. Monthly oil price and MSCI G7 stock returns
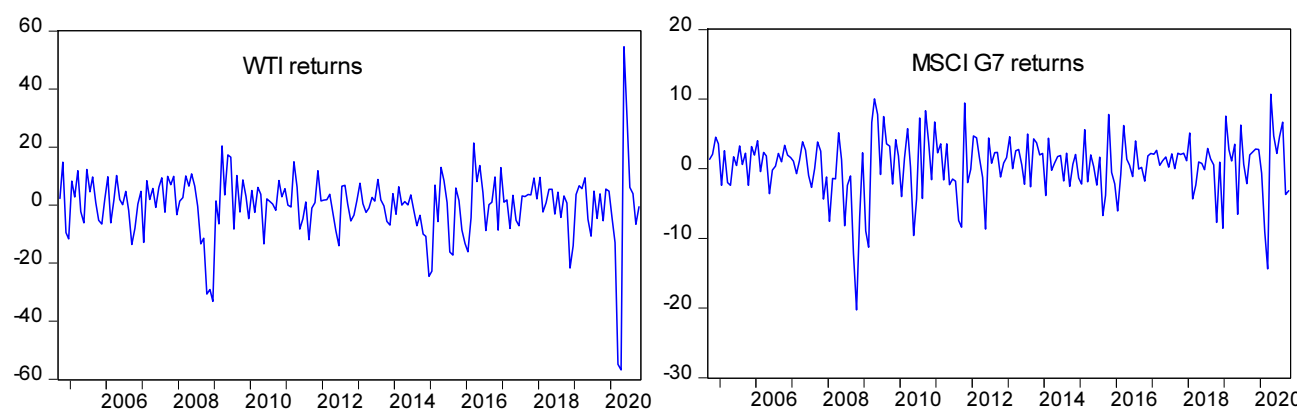

Table 1 provides the descriptive statistics and preliminary tests for the prices, returns, and 
positive and negative returns of the two key variables. Throughout the study period, the oil price average is about $\$ 70$, while the stock index of the G7 countries is about $\$ 1,375$. Focusing on the returns series, we observe that the average returns are negative and positive for the oil and stock index, respectively, suggesting that the G7 stock markets provide a more beneficial investment opportunity. The standard deviation indicates that oil returns are more volatile by a standard deviation of $11.34 \%$. Moreover, the skewness and kurtosis values, with high Jarque-Bera test statistics values, strongly reject the normality of all the price, returns, and positive/negative returns. We also find that the unit root test statistics indicate the presence of unit roots in the price series, while the returns and positive/negative returns are stationary. Since the study's data cover a long period, we conduct a preliminary analysis using the ADF unit root tests with structural breaks. The results in Table 1 indicate that the null hypothesis of the presence of unit roots is strongly rejected for the returns, positive returns, and negative returns series.

Table 1. Descriptive Statistics and Preliminary Tests

\begin{tabular}{|c|c|c|c|c|c|c|c|c|}
\hline & \multicolumn{2}{|c|}{ Prices } & \multicolumn{2}{|c|}{ Returns } & \multicolumn{2}{|c|}{ Positive returns } & \multicolumn{2}{|c|}{ Negative returns } \\
\hline & WTI & MSCI G7 & WTI & MSCI G7 & WTI & MSCI G7 & WTI & MSCI G7 \\
\hline Mean & 69.7756 & 1375.906 & -0.0674 & 0.4300 & 3.7139 & 1.8423 & -3.7812 & -1.4122 \\
\hline Median & 64.5700 & 1299.180 & 1.3554 & 1.1422 & 1.3554 & 1.1422 & 0.0000 & 0.0000 \\
\hline Maximum & 133.880 & 2268.070 & 54.5621 & 10.6743 & 54.5621 & 10.6743 & 0.0000 & 0.0000 \\
\hline Minimum & 16.550 & 653.3700 & -56.8125 & -20.2557 & 0.0000 & 0.0000 & -56.8125 & -20.2557 \\
\hline Std. Dev. & 22.641 & 367.765 & 11.3407 & 4.3658 & 6.0304 & 2.2768 & 8.0008 & 2.9404 \\
\hline Skewness & 0.3960 & 0.4443 & -0.9357 & -1.0705 & 4.0199 & 1.5003 & -3.8030 & -3.0488 \\
\hline Kurtosis & 2.4632 & 2.2866 & 10.7975 & 5.8755 & 29.3968 & 5.0483 & 21.5935 & 14.3261 \\
\hline Jarque-Bera & 7.3997 & 10.4984 & 519.783 & 103.888 & 6154.902 & 106.695 & 3262.186 & 1337.492 \\
\hline p-value & 0.0247 & 0.0052 & 0.0000 & 0.0000 & 0.0000 & 0.0000 & 0.0000 & 0.0000 \\
\hline $\mathrm{ADF}$ & -2.8436 & -0.5108 & -10.3278 & -12.1271 & -11.3305 & -13.8799 & -8.0680 & -10.0747 \\
\hline PP & -2.4897 & -0.4601 & -9.9281 & -12.1423 & -11.1350 & -13.8951 & -7.6482 & -10.2081 \\
\hline $\mathrm{ADF}-\mathrm{SB}$ & -2.3441 & -0.4432 & -12.0771 & -13.4755 & -13.0286 & -4.9491 & -9.3242 & -12.2572 \\
\hline
\end{tabular}

Note. This table provides the descriptive statistics and preliminary tests of oil prices and G7 stock markets (prices, returns, positive returns, and negative returns). The data cover from September 2004 to October 2020. ADF denotes statistics of the Augmented Dickey-Fuller test. PP denotes Phillips-Perron test statistics. KPSS denotes Kwiatkowski-Phillips-Schmidt-Shin test statistics. ADF-SB denotes statistics of the Augmented Dickey-Fuller test with structural breaks.

\section{B. Methodology}

\section{Bootstrap full-sample causality test}

Following Balcilar et al. (2010), we study the causal relationship between the MSCI G7 stock index and oil prices using the bootstrap rolling window Granger causality test. Engle 
and Granger (1987) show that the Granger non-causality test allows us to verify whether the information set for one variable improves the prediction of another variable and vice versa. However, if the time series are non-stationary, they may generate a non-standard asymptotic distribution. Hence, we perform the Toda and Yamamoto (1995) modified Wald test of the bivariate VAR model on rolling-window sub-samples. The Toda and Yamamoto method can be used regardless of the integration order of the variables. One disadvantage of standard Granger causality tests is that they are inappropriate for small samples and may produce non-asymptotic critical values. To overcome this problem, we employ the residual-based bootstrap (RB) method proposed by Shukur and Mantalos (2004). Shukur and Mantalos (2000) show that small sample modified-LR tests provide better power and size properties, even in small samples. Consequently, we use the RB-based modified-LR method to investigate the causal relationship between the MSCI G7 stock index and oil prices.

The bivariate $\operatorname{VAR}(\mathrm{p})$ process is specified as follows:

$$
y_{t}=\varnothing_{0}+\varnothing_{1} y_{t-1}+\ldots+\varnothing_{p} y_{t-(p+1)}+\epsilon_{t} ; \quad t=1,2, \ldots, T
$$

where $\epsilon_{t}=\left(\epsilon_{1 t}, \epsilon_{2 t}\right)^{\prime}$ is the white noise process with zero mean and covariance matrix $\Sigma$. $y_{t}=\left(G 7_{t}, O i l_{t}\right)^{\prime}$, where $G 7$ is the MSCI G7 stock index and Oil is the oil price.

Equation (1) can be expressed as follows:

$$
\left[\begin{array}{l}
O i l_{t} \\
G 7_{t}
\end{array}\right]=\left[\begin{array}{l}
\varnothing_{10} \\
\varnothing_{20}
\end{array}\right]+\left[\begin{array}{l}
\varnothing_{11}(L) \varnothing_{12}(L) \\
\varnothing_{21}(L) \varnothing_{22}(L)
\end{array}\right]\left[\begin{array}{l}
O i l_{t} \\
G 7_{t}
\end{array}\right]+\left[\begin{array}{c}
\epsilon_{1 t} \\
\epsilon_{2 t}
\end{array}\right]
$$

where $\varnothing_{i j}(L)=\sum_{k=1}^{p} \varnothing_{i j, k} L^{k}, i, j=1,2$ and $\mathrm{L}$ is a lag operator, and there is $L^{k} x_{t}=x_{t-k}$.

Based on Equation (2), the null hypothesis that the oil price (Oil) does not Granger cause MSCI G7 stock index $(G 7)$ is $\varnothing_{12, k}=0$ for $\mathrm{k}=1,2, \ldots \ldots$, p. Similarly, the null hypothesis that $G 7$ does not Granger cause $W T I$ is $\varnothing_{21, k}=0$ for $\mathrm{k}=1,2, \ldots \ldots, \mathrm{p}$. Thus, WTI is the Granger cause of $G 7$ and vice versa if these hypotheses are rejected.

\section{Parameter stability test}

Using the full-sample causality test requires the absence of structural changes in the parameters in the VAR models, as time-varying parameters lead to incorrect conclusions (Zeileis et al., 2005). Thus, we perform a parameter stability test to check for the existence of structural changes. The Exp-F, Mean-F, and Sup- $F$ tests are conducted to examine the short-run parameter stability (Andrews, 1993; Andrews and Ploberger, 1994). In addition, The $L c$ test is employed 
to examine the long-term stability of the VAR system (Hansen, 1992; Nyblom, 1989). If the parameters are time-varying, this indicates that we should employ the sub-sample test to investigate the Granger causal relationship between Oil and G7.

\section{Bootstrap sub-sample rolling-window causality test}

If the assumption of parameter stability is rejected, Balcilar et al. (2010) propose dividing the entire time series into sub-samples based on the rolling-window width $l$. This approach takes into account the variation in the causal relationship between variables over time and observes the instability due to structural changes between different sub-samples (Wang et al., 2020a). The RB-based modified-LR test is then conducted to examine the causal relationship between the variables in the sub-samples. The bootstrap $p$-values and LR statistics for the $T-l$ sub-samples permit us to identify the time variations in the causal relationship between the two series. $N_{b}^{-1} \sum_{k-1}^{p} \widehat{\varnothing}_{12, k}^{*}$ and $N_{b}^{-1} \sum_{k-1}^{p} \widehat{\varnothing}_{21, k}^{*}$ denote the average of a large number of estimations, indicating the impact of $O i l$ on $G 7$ and the effect of $G 7$ on oil prices, respectively. $N_{b}$ represents the number of bootstrap repetitions, and $\hat{\varnothing}_{12, k}^{*}$ and $\hat{\varnothing}_{21, k}^{*}$ are the bootstrap estimates from the VAR models. Next, we calculate the $90 \%$ confidence intervals, where the lower and upper bounds equal the 5th and 95th quantiles of each of $\hat{\varnothing}_{12, k}^{*}$ and $\hat{\varnothing}_{21, k}^{*}$, respectively.

\section{Results and discussion}

\section{A. Symmetric causality results}

\section{Full-sample causality analysis}

Based on Equation (2), the bivariate VAR process is used to investigate the full-sample Granger causality between the MSCI G7 stock index and oil prices. The optimal lag order selected is 1 based on Schwarz Information Criteria (SIC). Table 2 displays the results of the RB-based modified-LR tests. According to bootstrap p-values, we find that the oil price Granger-causes the MSCI G7 index at the 1\% level, while the MSCI G7 index has no predictive power on the oil price. These preliminary results contradict those found by Lee et al. (2012) concerning the first direction from oil prices to the G7 stock index but are partially in line with this study's results for the second direction. Lee et al. (2012) report that oil price changes do not Granger-cause composite stock price changes in G7 countries. Nonetheless, the causality from the stock indices to oil prices is significant only for Germany, the UK, and the US. 
Our findings are also consistent with those of Çevik et al. (2018), who find a significant causality running from the WTI to MSCI G7 stock market returns.

Table 2. Full Sample Granger Causality Tests: Bootstrap LR Test

\begin{tabular}{cccccc}
\hline Test & H0: Oil does not Granger cause G7 index & & H0: G7 index does not Granger cause Oil \\
\cline { 1 - 2 } \cline { 5 - 6 } & Statistic & p-value & & Statistic & p-value \\
\hline Bootstrap LR test & $36.0982^{* * *}$ & 0.0000 & & 3.8731 & 0.1470 \\
\hline$* * *$ denotes significance at $1 \%$. & & &
\end{tabular}

The Granger causality test assumes that the parameters in the VAR process are stable. Therefore, it is suitable to perform the full-sample Granger causality test between the MSCI G7 index and oil prices if these two variables and the VAR system have structural changes (Balcilar \& Ozdemir, 2013). We use the Sup-F, Mean-F, and Exp-F tests to examine the short-run stability of the parameters (Andrews, 1993; Andrews \& Ploberger, 1994). We also employ the $L c$ test to check the long-term stability of the VAR system (Hansen, 1992; Nyblom, 1989). The results of the parameter stability tests are reported in Table 3. The Sup-F test reveals sudden structural changes in both the oil price equation and the VAR system at the $1 \%$ level and in the MSCI G7 index at the 5\% level. The Exp-F and Mean-F tests show that the parameters may evolve gradually along the time trajectory in both the oil price equation and the VAR system at the $1 \%$ level and in the MSCI G7 index at the $10 \%$ level. Moreover, the Lctest shows that the parameters in the VAR system follow a random walk process at the $1 \%$ level. Thus, we find a time-varying causal relationship between the MSCI G7 index and the oil price. Consequently, we employ the subsample bootstrap rolling-window granger causality method to examine this causal relationship. To ensure accuracy, we choose a rolling window of 24 months. ${ }^{3}$ )

Table 3. Parameter Stability Tests

\begin{tabular}{|c|c|c|c|c|c|c|}
\hline & \multicolumn{2}{|c|}{ G7 index equation } & \multicolumn{2}{|c|}{ Oil equation } & \multicolumn{2}{|c|}{ VAR system } \\
\hline & Statistics & $\mathrm{p}$-value & Statistics & $\mathrm{p}$-value & Statistics & $\mathrm{p}$-value \\
\hline Sup-F & $2.8581^{* *}$ & 0.0400 & $5.7007 * * *$ & 0.0005 & $4.7020 * * *$ & 0.0015 \\
\hline Exp-F & $0.8035^{*}$ & 0.0535 & $1.5042 * * *$ & 0.0005 & $1.1562 * * *$ & 0.0055 \\
\hline Mean-F & $1.5361^{*}$ & 0.0545 & $2.3314 * * *$ & 0.0015 & $2.0591 * * *$ & 0.0080 \\
\hline$L c$ & & & & & $1.4733^{* * *}$ & 0.0003 \\
\hline
\end{tabular}

$* * *, * *$, and $*$ denote significance at the $1 \%, 5 \%$, and $10 \%$ levels, respectively.

p-values are calculated using 10,000 bootstrap repetitions.

3) We also employ the bootstrap rolling window causality test for windows of 20,28 , and 32 weeks, and obtain similar results. 


\section{Time-varying causality analysis}

Fig. 3 presents the results of the time-varying causality tests between oil and stock index returns. The first row of Fig 3 presents the estimated p-values of the LR statistic. The bootstrap p-values for the causality test from oil to MSCI G7 stock index returns are shown in panel (a), while the p-values of the second directional causality are shown in panel (c). The second row of the figure indicates the sign of the causality in the two directions. In this figure, the horizontal axes show the period starting from the first rolling window to the end of the sample period. The null hypothesis of no causality running from one variable to another is rejected at the $10 \%$ level when the p-values are below the horizontal red dashed line. A close look at the results of this test shows that the causal relationship between oil prices and the MSCI G7 stock market is time-dependent. In fact, we observe that the presence and absence of the causality between the two variables in the two directions are both time-dependent. This finding indicates that the causality between oil and stock markets cannot be modeled constantly but only from a time-varying perspective.

Starting with the causality running from oil prices to the stock index, the results in Fig. 4a show that the null hypothesis is rejected during the periods 2008M10-2009M2, 2009M5-

Figure. 3. Rolling window estimation results for relation between MSCI G7 index and oil price
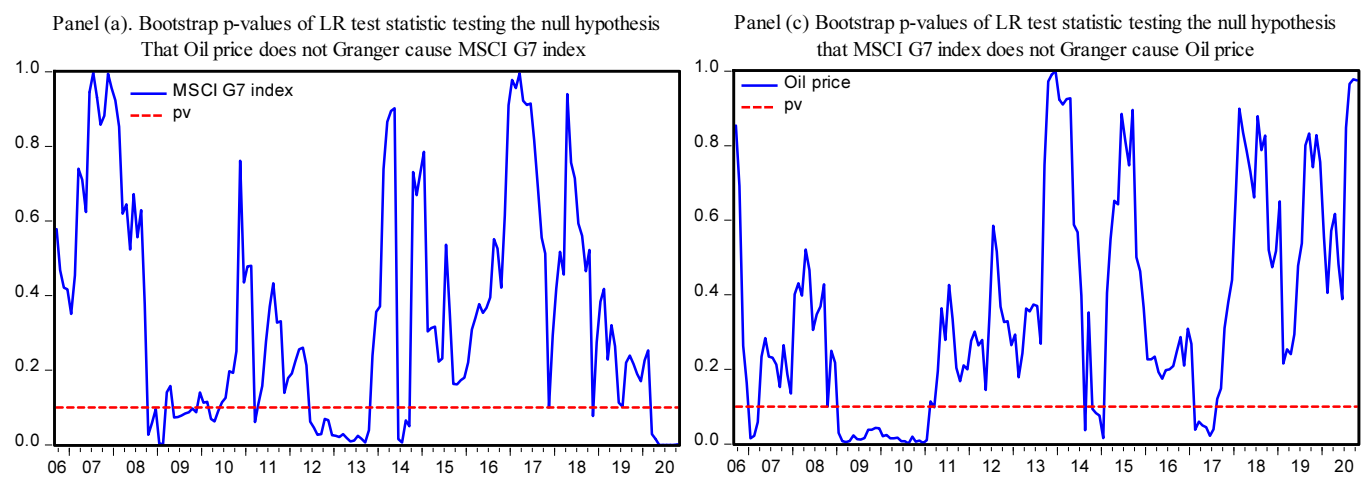

Panel (b) Bootstrap estimation of the sum of the rolling coefficients for the impactof Oil price on MSCI G7 index

Panel (d) Bootstrap estimation of the sum of the rolling coefficients for the impactof MSCI G7 index on Oil price
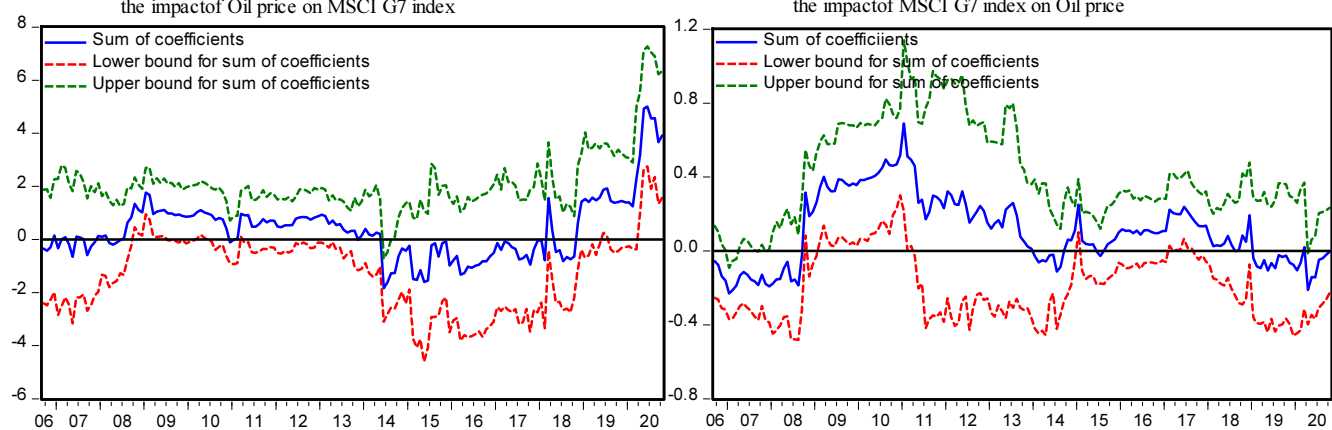
2009M11, 2010M3-2010M5, 2011M3, 2012M6-2013M10, 2014M6-2014M9, 2018M11, and 2020M3-2020M10.

The first period of causality coincides with the period of the global financial crisis. During this crisis period, the oil price increased steeply, allowing it to acquire a predictive power for the stock markets and most economic and financial variables. Moreover, the stock markets of the G7 countries were strongly affected by the evolution of oil prices during this period (Çevik et al., 2018). On the other hand, we detect a set of periods of non-causality from oil to G7 stock markets, especially over the periods from end-2006 and 2008 and the period spanning between end-2014 and the beginning of 2020. This result contradicts the full sample Granger causality test results presented above in Table 2, based on the full sample period, which implies that the oil price causes the G7 stock markets "on average" during the full period and fails to identify the periods for which the causal link may not exist. Our results are consistent with Çevik et al. (2018), who find that the causality from the oil price to G7 stock prices is most significant during the global financial crisis.

On the other hand, the results report that the longest period of causality running from the oil price to G7 stock markets occurs between 2012 and 2013. This period was characterized by oil price stability and increased the MSCI G7 stock index, giving oil prices a predictive power for the stock markets. This finding can be explained by the fact that investor decisions and cash flows predictions, the main determinants of stock prices, are made based on the situation in the oil market. Moreover, this period followed the debt crisis and the global financial crisis, from which investors learned a lesson about the linkage between oil prices and stock markets, which intensifies steeply during financial stress periods and economic downturns (Baruník et al., 2016; Ftiti et al., 2016; Mokni, 2020b; Reboredo \& Rivera-Castro, 2014; Turhan et al., 2014; Youssef \& Mokni, 2019).

The results also suggest that the oil price Granger causes the G7 countries' stock markets from March 2020 to October 2020, during the ongoing COVID-19 pandemic. This period is characterized by a high degree of uncertainty about the novel coronavirus and a steep decline in oil prices due to problems in the global economy. Therefore, we observe an increase in the co-movement between oil prices and the MSCI G7 stock index, indicating that falling oil prices act as a negative signal for the stock market (Prabheesh et al., 2020b). A significant influence of oil prices on G7 stock markets is thus evident. Our finding for the COVID-19 period confirms the previous findings of Salisu et al. (2020), suggesting that oil and stock markets may both experience greater initial and prolonged impacts during the COVID-19 pandemic. Similarly, Prabheesh et al. (2020a) claimed that an oil price decline leads to lower stock returns in oil-exporting countries due to the lower future earnings for oil companies, exhibiting a signal of reduced aggregate demand and economic activity in these countries.

The results regarding causality from the MSCI G7 stock index to oil price returns show 
significant causality in the periods between January 2007 and March 2007, between January 2009 and January 2011, end-2014, and between January and June 2017. This causality may be due to the global financial crisis and the European debt crisis, events during which most stock indices declined. This situation makes the G7 stock markets a signal for oil price fluctuations. The significance of the causality between stock markets and oil prices is derived only from bearish or bullish market conditions (Ding et al., 2016). The second period of causality from the G7 stock markets to oil prices covers 2014 and 2017.

Our results are in line with those of Jammazi et al. (2017), who claim that this significant causal linkage during different periods results from the integration between oil and stock markets, due mainly to the financialization of commodity markets; accordingly, oil prices respond significantly to the information in stock markets and vice versa. Other reasons cited to explain this relationship include investors' behavior and investment preferences (Turhan et al., 2014), aggressive investor movements (Baruník et al., 2016), and electronic trading platforms (Jammazi et al., 2017). Moreover, the MSCI stock index considered in this study represents the stock markets of G7 countries, the majority of which are oil-importing. The predominance of demand-side shocks in these countries' economic development leads to oil market performance, supporting the linkage between oil prices and stock markets in these countries.

Our results are also similar to those of Huang et al. (2015), who examine Chinese stock markets. Huang et al. (2015) report a significant bidirectional causal relationship between oil prices and the sectoral stock indices in China in the two directions. Our results also conform completely or partially to those of Arouri and Nguyen (2010), Anoruo (2011), Lee et al. (2012), and Ajmi et al. (2014), as well as, more recently, those of Ding et al. (2016), Bahmani-Oskooee et al. (2019), and Xiao and Wang (2020), who find a significant relationship between oil prices and stock markets using a Granger causality approach.

The second row of Fig. 3 presents the sign of the bidirectional causality expressed by the bootstrap estimation of the sum of the rolling coefficient indicating the impact of a variable on the other. In both directions, we observe that each variable's effect on the other is time-varying and that the sign of this effect changes from one period to another. In fact, the effect of oil prices on the G7 stock index is low and negative at the beginning of the estimation period (from 2006 to 2008). This result is explained by the small increase in the oil price during this period, making its influence weak and insignificant. However, during the period from 2008 to 2014, we observe a positive and significant effect of the oil price on the G7 stock markets, indicating that a rise in oil price leads to a stock market appreciation. Oil price instability and commodity financialization can explain this finding. This behavior makes the oil price a fundamental determinant of global stock markets. An increase in the oil price is interpreted by stock market investors as good news and makes them optimistic about the global economic situation. As a result, analysts predict more cash flows, leading to stock market 
appreciation (Jones \& Kaul, 1996; Mokni, 2020b; Nusair \& Khasawneh, 2017). The effect of the oil price becomes negative between 2014 and 2018 as it declines. Within this period, the price of oil reached very low values in 2015. At the end of the study period, we find that the oil price effect becomes positive with a significant increase during the COVID-19 period. This increased effect may be due to the dramatic decline in oil prices during the pandemic. Moreover, the increased uncertainty because of the COVID-19 pandemic induces investors to make decisions based on fundamental economic indicators such as the oil price, leading to a high degree of integration between oil and stock markets in G7 countries, the nations most affected by the virus (Youssef et al., 2021).

The results regarding the effect of the stock markets on the oil price show that the G7 stock returns have a generally positive effect during most of the period. Moreover, we find that this effect increases significantly during the global financial and European debt crises. During these crisis periods, an increase in the stock market indices is an indication of increased firm value, especially for firms that use oil as a production input. Thus, oil demand increases, and oil prices also increase.

\section{B. Asymmetric causality results}

Hatimi-J et al. (2017), Bahmani-Oskooee et al. (2019), and Wang et al. (2020b) are among the studies that report an asymmetric causality between oil prices and stock markets. To conduct a more in-depth analysis, we investigate whether these findings are still valid in a time-varying context. We test the presence of an asymmetric causal relationship between the oil price and MSCI G7 stock returns using the bootstrap rolling window Granger causality method. We consider positive and negative changes in oil and stock index returns, and we apply the same time-varying Granger causality test between the two variables by investigating the causality from positive/negative changes of each variable to the other. We separate the causal relationships running from positive and negative changes to detect a possible asymmetric causal link. The asymmetric causality occurs when it is significant for positive (negative) changes and not significant for negative (positive) ones.

The results of the time-varying Granger-causality from positive and negative changes in oil (stock index) returns to the stock index (oil) returns are shown in Fig. 4 (5). There is substantial evidence of Granger causality running from positive and negative oil price changes to the MSCI G7 stock index over several periods. In particular, Fig. 4 (panel a) shows that positive oil price changes Granger-cause the MSCI G7 stock index during about $20 \%$ of the total period (34 months among 170). This causality is significant over the periods 2006M122007M1, 2008M7, 2010M9, 2011M3, 2012M8, 2013M1-2013M9, 2014M12-2015M5, 2015M92016M1, and 2020M5-2020M10. The longest period of causality from positive oil price changes 
or positive oil price shocks is observed in 2013 (a period of oil price stability), 2014-2015, and 2020, when oil prices declined significantly. In the periods of overall oil price decline, an increase in oil prices impacts investor sentiment by raising investor morale, leading to stock market appreciation. This finding is confirmed by the panel (b) of Fig. 4, which shows a positive effect of oil price increases on MSCI G7 returns during significant causality periods.

Figure. 4. Asymmetric bootstrap rolling window causality test from oil price to MSCI G7 index



The results regarding the causality from negative oil price changes to G7 stock markets returns are shown in Fig. 5. We observe a significant causality over the periods 2008M8, 2009M2- 2010M5, 2013M9-2014M1, 2018M11-2018M12, 2019M07, and 2020M3-2010M10. The longest period coincides with the global financial crisis and COVID-19 pandemic. This finding is explained by the fact that financial markets are more integrated and more dependent during periods of turmoil (Bahmani-Oskooee et al., 2019; Ding et al., 2016; Mokni, 2020b; Xiao \& Wang, 2020). Similarly to the positive oil price changes, panel (c) of Fig. 4 indicates that the effect of negative oil shocks on MSCI G7 returns is generally positive over the periods of causality. On the other hand, while the periods of causality from positive oil shocks differ from those from negative shocks, the results for the COVID-19 pandemic period reveal significant causality from the two types of shocks to G7 stock returns, indicating symmetric causality 
from oil prices to G7 stock markets during the ongoing health crisis. However, we observe an asymmetric causality during the global financial crisis and other periods generally in 2013 and 2014, expressed by significant causal links proceeding only from positive or negative shocks.

Figure. 5. Asymmetric bootstrap rolling window causality from and MSCI G7 index to oil price

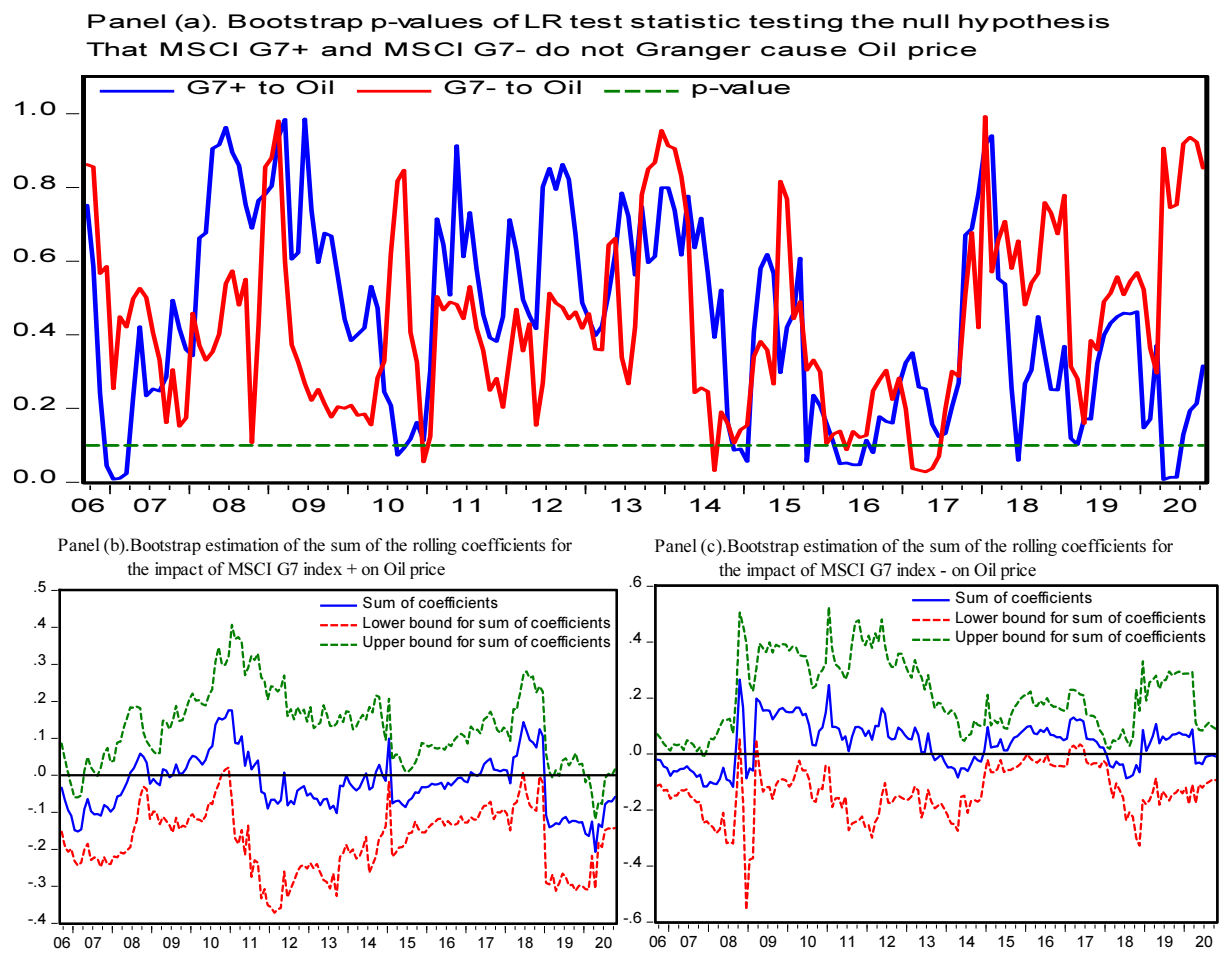

Fig. 5 shows the results for the second direction of causality, running from the positive and negative shocks of the MSCI G7 stock index to oil returns. The results show limited periods of significant causality compared to the first direction. Positive and negative changes in the stock index Granger-cause oil returns for only around $11 \%$ and $5 \%$ of the period, respectively. Specifically, positive changes in G7 stock markets Granger-cause oil returns in 2007, 2014, 2016, and 2020, while the negative changes have a limited predictive power between February and June 2017. Moreover, the difference between the causal effects from positive and negative stock returns changes shows evidence of an asymmetric causality from the MSCI G7 stock markets and the oil market.

The results on the effects of increases and decreases in the G7 stock market index on oil returns (see panels $\mathrm{b}$ and $\mathrm{c}$ of Fig. 5) during the periods of significant causality show that positive (negative) shocks in the stock markets impact oil returns positively (negatively).

Overall, we find an asymmetric causality between oil prices and stock markets in the G7 
countries. This result confirms a large body of literature that has found that the relationship between oil prices and stock markets is asymmetric. This asymmetric relationship can be explained with reference to several channels. The first is cash flows, which can impact dividends and the stock market. The second is interest rates. Oil price changes directly impact inflation, which influences monetary policy. Therefore, as the main determinant of cash flows, the interest rate might behave differently following an oil price increase than it would following a decrease, implying an asymmetric effect on stock prices (Bahmani-Oskooee et al., 2019). Another explanation of this relationship is related to behavioral factors, given that an increase in the oil price is interpreted differently than a decrease. Therefore, the impact of oil prices is asymmetric between the sign of the shocks (Mokni, 2020b; Nusair \& Khasawneh, 2017).

Our findings are consistent with those of Nusair and Khasawneh (2017) and Mokni (2020b), who find that oil price changes impact stock markets differently according to the shock's sign. In addition, our findings confirm previous studies that have found that oil price changes exert an asymmetric effect on stock markets using other methodologies, such as the nonlinear ARDL model (Al-hajj et al., 2018; Bahmani-Oskooee et al., 2019; Kisswani et al., 2017; Salisu \& Isah, 2017) and quantile regression (Lee \& Zeng, 2011). However, our results contradict those of Park and Ratti (2008), Cong et al. (2008), Nandha and Faff (2008), and Reboredo and RiveraCastro (2014), who fail to find an asymmetric relationship between oil prices and stock markets.

\section{Conclusion}

The literature investigating the relationship between oil prices and stock markets is growing due to the importance of this relationship for investors and policymakers. The results are mixed because of differences in the methodologies used, the periods considered, and the oil and stock market data examined. This study adds to this literature by investigating this relationship based on the symmetric and asymmetric Granger causality in a time-varying framework. We employed a bootstrap rolling window procedure to offer an in-depth analysis of the predictive power of oil prices and MSCI stock markets in G7 countries.

The results of this study are as follows. By applying a full sample Granger causality test, we find that the oil price causes MSCI G7 index returns, while the latter has no predictive power on oil returns. Moreover, by testing the causality in a symmetric and asymmetric time-varying framework, we find that the causal link between WTI oil prices and the MSCI G7 stock market is time-dependent. The periods of bidirectional causality coincide with the global financial crisis, which followed the European debt crisis (between 2012 and 2013), and the ongoing COVID-19 pandemic.

We also decompose the oil price and stock index returns into positive and negative changes 
to verify the possibility of an asymmetric causal link between the two markets. We find that the causality running from oil prices to G7 stock markets is asymmetric, expressed by different patterns of positive and negative oil shocks. Similar results are found for the causality from stock returns to oil prices. The results also suggest symmetric causality during the COVID-19 pandemic.

Our findings offer important implications for investors and policymakers. First, investors can use our findings in their asset allocation and portfolio design, and hedging strategies. Investors should be aware of the dynamic relationship reflected in the time-varying causality running between the oil and stock markets, and their decisions should be made from an appropriately dynamic perspective. The significant causal relationships observed during the periods of turmoil and the financial crisis suggest that oil can act as a hedge and safe haven against adverse conditions in stock markets, thus reducing potential diversification benefits for investors. On the other hand, investors and policymakers should pay special attention to the linkage and feedback between the oil and stock markets. Combining oil and stock assets in portfolios usually does not offer a beneficial portfolio design and hedging opportunity. Moreover, investors' and policymakers' decisions concerning oil and stock market investment and regulation should differentiate between positive and negative shocks, as their impacts differ.

Our study has several limitations, mainly related to the data on G7 stock markets, which are considered in an aggregated index. Future studies could extend the scope of our analysis by considering individual G7 countries to reduce the aggregation bias and identify time-variation and heterogeneity in the relationship between G7 stock markets and oil prices. Disaggregating the data by considering the stock index of each country separately can provide a more comprehensive picture of the causal relationship between oil prices and G7 stock markets; it might show a divergence between oil-importing and oil-exporting countries' stock markets in response to oil price fluctuations (Mokni, 2020a, b). Moreover, future research could consider using other time-varying causality tests, such as that recently developed by Shi et al. $(2018,2020)$.

\section{References}

Abhyankar, A., Xu, B. \& Wang, J. Y. (2013). Oil price shocks and the stock market: Evidence from Japan. The Energy Journal, 34, 199-222.

Ajmi, A.D., El-Montasser, G., Hammoudeh, S., \& Nguyen, D.C. (2014). Oil prices and MENA stock markets: New evidence from nonlinear and asymmetric causalities during and after the crisis period. Applied Economics, 46, 2167-2177.

Al-hajj, E., Al-Mulali, U., \& Solarin, S.A. (2018). Oil price shocks and stock returns nexus for Malaysia: Fresh evidence from nonlinear ARDL test. Energy Reports, 4, 624-637. 
Andrews, W. (1993). Tests for parameter instability and structural change with unknown change point. Journal of the Econometric Society, 61(4), 821-856.

Andrews, W., \& Ploberger, W. (1994). Optimal tests when a nuisance parameter is present only under the alternative. Journal of the Econometric Society, 62(6), 1383-1414.

Anoruo, E. (2011). Testing for linear and nonlinear causality between crude oil price changes and stock market returns. International Journal of Economic Sciences and Applied Research, 4(3), 75-92.

Arouri, M. E. H., \& Nguyen, D. K. (2010). Oil prices, stock markets and portfolio investment: Evidence from sector analysis in Europe over the last decade. Energy Policy, 38, 4528-4539

Asalman, Z. \& Herrera, A. M. (2015). Oil price shocks and the US stock market: Do sign and size matter? Energy Journal, 36(3), 171-188.

Badeeb, R. A., \& Lean, H. H. (2018). Asymmetric impact of oil price on Islamic sectoral stocks. Energy Economics, 71, 128-139.

Bahmani-Oskooee, M., Ghodsi, S. H., \& Hadzic, M. (2019). Asymmetric causality between oil price and stock returns: A sectoral analysis. Economic Analysis and Policy, 63, 165-174.

Balcilar, M., \& Ozdemir, Z. A. (2013). The export-output growth nexus in Japan: A bootstrap rolling window approach. Empirical Economics, 44(2), 639-660.

Balcilar, M., Gupta, R., Wang, S., \& Wohar, M. E. (2020). Oil price uncertainty and movements in the US government bond risk premia. North American Journal of Economics and Finance, 52, 101147.

Balcilar, M., Ozdemir, Z. A., \& Arslanturk, Y. (2010). Economic growth and energy consumption causal nexus viewed through a bootstrap rolling window. Energy Economics, 32(6), 1398-1410.

Baruník, J., Kočenda, E., \& Vácha, L. (2016). Gold, oil, and stocks: Dynamic correlations. International Review of Economics \& Finance, 42, 186-201.

Basher, S. A., \& Sadorsky, P. (2006). Oil price risk and emerging stock markets. Global Finance Journal, $17(2), 224-251$.

Basher, S. A., Haug, A. A., \& Sadorsky, P. (2012). Oil prices, exchange rates and emerging stock markets. Energy Economics, 34(1), 227-240.

Basher, S. A., Haug, A. A., \& Sadorsky, P. (2018). The impact of oil-market shocks on stock returns in major oil-exporting countries. Journal of International Money and Finance, 86, 264-280.

Bastianin, A., Conti, F., \& Manera, M. (2016). The impacts of oil price shocks on stock market volatility: Evidence from the G7 countries. Energy Policy, 98, 160-169.

Bouoiyour, J., Selmi, R., Shahzad, S. J. H., \& Shahbaz, M. (2017). Response of stock returns to oil price shocks: Evidence from oil importing and exporting countries. Journal of Economic Integration, 32(4), 913-936.

Cashin, P., Mohaddes, K., Raissi, M., \& Raissi, M. (2014). The differential effects of oil demand and supply shocks on the global economy. Energy Economics, 44, 113-134.

Çevik, E. İ., Atukeren, E., \& Korkmaz, T. (2018). Oil prices and global stock markets: A time-varying causality-in-mean and causality-in-variance analysis. Energies, 11(10), 2848.

Cheema, M. A., \& Scrimgeour, F. (2019). Oil prices and stock market anomalies. Energy Economics, $83,578-587$.

Chen, J., Jin, F., Ouyang, G., Ouyang, J., \& Wen, F. (2019). Oil price shocks, economic policy uncertainty 
and industrial economic growth in China. PloS one, 14(5), e0215397.

Chen, N-F., Roll, R., \& Ross, S. A. (1986). Economic forces and the stock market. The Journal of Business, 59(3), 383-403.

Cong, R. G., Wei, Y. M., Jiao, J. L., \& Fan, Y. (2008). Relationships between oil price shocks and stock market: An empirical analysis from China. Energy Policy, 36(9), 3544-3553.

Creti, A., Ftiti, Z., \& Guesmi, K. (2014). Oil price and financial markets: Multivariate dynamic frequency analysis. Energy Policy, 73, 245-258.

Cunado, J., \& De Gracia, F. P. (2014). Oil price shocks and stock market returns: Evidence for some European countries. Energy Economics, 42, 365-377.

Degiannakis, S., Filis, G., \& Arora, V. (2018). Oil prices and stock markets: a review of the theory and empirical evidence. The Energy Journal, 39(5), 85-130.

Ding, H., Kim, H. G., \& Park, S. Y. (2016). Crude oil and stock markets: Causal relationships in tails? Energy Economics, 59, 58-69.

Driesprong, G., Jacobsen, B., \& Maat, B. (2008). Striking oil: Another puzzle? Journal of Financial Economics, 89, 307-327.

Engle, R. F., \& Granger, C. W. J. (1987). Co-integration and error correction: Representation, estimation, and testing. Econometrica, 55, 251-276.

Ftiti, Z., Guesmi, K., \& Abid, I. (2016). Oil price and stock market co-movement: What can we learn from time-scale approaches? International Review of Financial Analysis, 46, 266-280.

Fufa, T. \& Kim, J. (2018). Stock markets, banks, and economic growth: Evidence from more homogeneous panels. Research in International Business and Finance, 44, 504-517.

Gaies, B., Nakhli, M.S., Sahut, JM., \& Guesmi, K. (2021). Is Bitcoin rooted in confidence? Unraveling the determinants of globalized digital currencies. Technological Forecasting and Social Change, 172, 121038.

Güntner, J. H. (2014). How do international stock markets respond to oil demand and supply shocks? Macroeconomic Dynamics, 18(8), 1657-1682.

Hamilton, J. D. (1983). Oil and the macroeconomy since World War II. Journal of Political Economy, 91(2), 228-248.

Hamilton, J. D. (2003). What is an oil shock? Journal of Econometrics, 113(2), 363-398.

Hansen, E. (1992). Test for parameter instability in regressions with I(1) processes. Journal of Business and Economic Statistics, 10, 321-336.

Hatemi-J., A., Al Shayed, A., \& Roca E. (2017). The effect of oil prices on stock prices: Fresh evidence from asymmetric causality tests. Applied Economics, 49(16), 1584-1592.

Hatemi-J., A. (2012). Asymmetric causality tests with an application. Empirical Economics, 43(1), 447-456.

Herrera A. M., Karaki M. B., \& Rangaraju, S. K. (2019). Oil price shocks and U.S. economic activity. Energy Policy, 129, 89-99.

Hooker, M. A. (1996). What happened to the oil price-macroeconomy relationship? Journal of Monetary Economics, 38(2), 195-213.

Huang, B.-N., Hwang, M. J., \& Peng, H.-P. (2005). The asymmetry of the impact of oil price shocks on economic activities: An application of the multivariate threshold model. Energy Economics, 27(3), 
455-476.

Huang, S., An, H., Gao, X., \& Huang, X. (2015). Identifying the multiscale impacts of crude oil price shocks on the stock market in China at the sector level. Physica A: Statistical Mechanics and its Applications, 434, 13-24.

Huang, Y., \& Guo, F. (2008). Macro shocks and the Japanese stock market. Applied Financial Economics, 18(17), 1391-1400.

Jammazi, R., Ferrer, R., Jareño, F., \& Shahzad, S. J. H. (2017). Time-varying causality between crude oil and stock markets: What can we learn from a multiscale perspective? International Review of Economics \& Finance, 49, 453-483.

Jammazi, R., \& Reboredo, J. C. (2016). Dependence and risk management in oil and stock markets. A wavelet-copula analysis. Energy, 107, 866-888.

Jiménez-Rodríguez, R. (2014). Oil price shocks and stock markets: Testing for non-linearity. Empirical Economics, 48, 1079-1102.

Jones, C.M., \& Kaul, G. (1996). Oil and the stock markets. The Journal of Finance, 51(2), 463-491.

Kang, W., Ratti, R.A., \& Yoon, K. H. (2015). Time-varying effect of oil market shocks on the stock market. Journal of Banking \& Finance, 61, S150-S163.

Kilian, L. (2009). Not all oil price shocks are alike: Disentangling demand and supply shocks in the crude oil market. American Economic Review, 99(3), 1053-1069.

Kilian, L., \& Park, C. (2009). The impact of oil price shocks on the U.S. stock market. International Economic Review, 50(4), 1267-1287.

Kilian, L., \& Vigfusson, R. J. (2013). Do oil prices help forecast US real GDP? The role of nonlinearities and asymmetries. Journal of Business \& Economic Statistics, 31(1), 78-93.

Kisswani, K. M., Elian, M. I., \& Kruse, R. (2017). Exploring the nexus between oil price and sectoral stock prices: Nonlinear evidence from Kuwait stock exchange. Cogent Economics \& Finance, 5(1), 1286061.

Kocaaslan, O. K. (2019). Oil price uncertainty and unemployment. Energy Economics, 81, 577-583.

Lee, B. J., Yang, C. W., \& Huang, B. N. (2012). Oil price movements and stock markets revisited: A case of sector stock price indexes in the G-7 countries. Energy Economics, 34(5), 1284-1300.

Lee, C. C., \& Zeng, J. H. (2011). The impact of oil price shocks on stock market activities: Asymmetric effect with quantile regression. Mathematics and Computers in Simulation, 81(9), 1910-1920.

Lee, C. C., Lee, C. C., \& Li, Y. (2020). Oil price shocks, geopolitical risks, and green bond market dynamics. The North American Journal of Economics and Finance, 55, 101309.

Lee, C. C., Lee, C. C., \& Wu, Y. (2021). The impact of COVID-19 pandemic on hospitality stock returns in China. International Journal of Finance and Economics, 1-14.

Liu, H., Manzoor, A., Wang, C., Zhang, L., \& Manzoor, Z. (2020a). The COVID-19 outbreak and affected countries stock markets response. International Journal of Environmental Research and Public Health, 17(8), 1-19.

Liu, L., Wang E. Z., \& Lee C. C. (2020b). Impact of the COVID-19 pandemic on the crude oil and stock markets in the US: A time-varying analysis. Energy Research Letters, 1(1). doi:10.46557/001c.13154

McKibbin W. J. \& Fernando, R. (2020). The global macroeconomic impacts of COVID-19: seven scenarios. 
Asian Economic Papers, MIT Press, 20(2), 1-30.

Miller, J. I., \& Ratti, R. A. (2009). Crude oil and stock markets: Stability, instability, and bubbles. Energy Economics, 31(4), 559-568.

Mokni, K. (2020a). A dynamic quantile regression model for the relationship between oil price and stock markets in oil-importing and oil-exporting countries. Energy, 213, 118639.

Mokni K. (2020b). Time-varying effect of oil price shocks on the stock market returns: evidence from oil-importing and oil-exporting countries. Energy Reports, 6, 605-619.

Mork, K. A. (1989). Oil and the macroeconomy when prices go up and down: an extension of Hamilton's results. Journal of political Economy, 97(3), 740-744.

Musgrove, P. (1981). The oil price increase and the alleviation of poverty: Income distribution in Caracas, Venezuela, in 1966 and 1975. Journal of Development Economics, 9(2), 229-250.

Nakhli, M.S., \& Gaies, B. (2021). Political risk and financial development in Nigeria: Can credit buy social peace? Evidence from NARDL approach. The Quarterly Review of Economics and Finance, $82,55-62$.

Nandha, M., \& Faff, R. (2008). Does oil move equity prices? A global view. Energy Economics, 30(3), 986-997.

Naranpanawa, A., \& Bandara, J. S. (2012). Poverty and growth impacts of high oil prices: Evidence from Sri Lanka. Energy Policy, 45, 102-111.

Narayan, P. K., \& Gupta, R. (2015). Has oil price predicted stock returns for over a century? Energy Economics, 48, 18-23.

Narayan, P. K., \& Narayan, S. (2010). Modelling the impact of oil prices on Vietnam's stock prices. Applied Energy, 87, 356-361.

Nusair, S., \& Al-Khasawneh, J. (2017). Oil price shocks and stock market returns of the GCC, countries: empirical evidence from quantile regression analysis. Economic Change and Restructuring, 51(4), 339-372.

Nyblom, J. (1989). Testing for the constancy of parameters over time. Journal of the American Statistical Association, 84, 223-230.

O'Neill, J. T., Penm, J., \& Terrell, D. R. (2008). The role of higher oil prices: A case of major developed countries. Research in Finance, 24, 287-299.

Papapetrou, E. (2001). Oil price shocks, stock market, economic activity and employment in Greece. Energy Economics, 23, 511-532.

Park, J., \& Ratti, R. A. (2008). Oil price shocks and stock markets in the US and 13 European countries. Energy Economics, 30(5), 2587-2608.

Phan, D. H. B., Sharma, S. S., \& Narayan, P. K. (2015). Oil price and stock returns of consumers and producers of crude oil. Journal of International Financial Markets, Institutions and Money, 34, 245-262.

Prabheesh, K. P., Garg, B., \& Padhan, R. (2020a). Time-varying dependence between stock markets and oil prices during COVID-19: The case of net oil-exporting countries. Economics Bulletin, 40(3), 2408-2418.

Prabheesh, K. P., Padhan, R., \& Garg, B. (2020b). COVID-19 and the oil price-stock market nexus: Evidence 
from net oil-importing countries. Energy Research Letters, 1(2), 13745.

Ramos, S.B., \& Veiga, H. (2013). Oil price asymmetric effects: Answering the puzzle in international stock markets. Energy Economics, 38, 136-145.

Rapsomanikis, G., Hallam, D., \& Conforti, P. (2003). Market integration and price transmission in selected food and cash crop markets of developing countries: Review and applications. Commodity Market Review 2003-2004. Retrieved from http://www.fao.org/DOCREP/006.Y5117E/y5117e06.htm

Reboredo, J. C., \& Rivera-Castro, M. A. (2014). Wavelet-based evidence of the impact of oil prices on stock returns. International Review of Economics \& Finance, 29, 145-176.

Sadorsky, P. (1999). Oil price shocks and stock market activity. Energy Economics, 21(5), 449-469.

Salisu, A. A., Ebuh, G. U., \& Usman, N. (2020). Revisiting oil-stock nexus during COVID-19 pandemic: Some preliminary results. International Review of Economics \& Finance, 69, 280-294.

Salisu, A. A., \& Isah, K. O. (2017). Revisiting the oil price and stock market nexus: A nonlinear panel ARDL approach. Economic Modelling, 66, 258-271.

Salisu, A. A., \& Oloko, T. F. (2015). Modelling oil price-US stock nexus: A VARMA-BEKKAGARCH approach. Energy Economics, 50, 1-12.

Scherer, F. M., \& Ross, D. (1990). Industrial market structure and economic performance (3rd ed.). Boston: Houghton Mifflin.

Shaikh, I. (2021). On the relation between the crude oil market and pandemic Covid-19. European Journal of Management and Business Economics, ahead-of-print. doi: 10.1108/EJMBE-08-2020-0223

Sharif, A., Aloui, C., \& Yarovaya, L. (2020). COVID-19 pandemic, oil prices, stock market, geopolitical risk and policy uncertainty nexus in the US economy: Fresh evidence from the wavelet-based approach. International Review of Financial Analysis, 70, 101496.

Shin, Y., Yu, B., \& Greenwood-Nimmo, M. (2014). Modelling asymmetric cointegration and dynamic multipliers in a nonlinear ARDL framework. In W. Horrace, \& R. Sickles (Eds.), Festschrift in honor of Peter Schmidt (pp. 281-314), Springer.

Shi, S. Hurn, S., \& Phillips, P. C. (2020). Causal change detection in possibly integrated systems: Revisiting the money-income relationship. Journal of Financial Econometrics, 18, 158-180.

Shi, S., Phillips, P.C., \& Hurn, S. (2018) Change detection and the causal impact of the yield curve. Journal of Time Series Analysis, 39(6), 966-987.

Shukur, G., \& Mantalos, P. (2000). A simple investigation of the Granger-causality test in integratedcointegrated VAR systems. Journal of Applied Statistics, 27(8), 1021-1031.

Shukur, G., \& Mantalos, P. (2004). Size and power of the RESET test as applied to systems of equations: A Bootstrap approach. Journal of Modern Applied Statistical Methods, 3(2), 370-385.

Štifanić, D., Musulin, J., Miočević, A., Baressi Šegota, S., Šubić, R., \& Car, Z. (2020). Impact of COVID-19 on forecasting stock prices: An integration of stationary wavelet transform and bidirectional long short-term memory. Complexity, 2020, 1-12.

Tchatoka, F. D., Masson, V., \& Parry, S. (2018). Linkages between oil price shocks and stock returns revisited. Energy Economics, 82, 42-61.

Toda, H. Y., \& Yamamoto, T. (1995). Statistical inference in vector autoregressions with possibly integrated processes. Journal of Econometrics, 66(1-2), 225-250. 
Turhan, M. I., Sensoy, A., Ozturk, K., \& Hacihasanoglu, E. (2014). A view to the longrun dynamic relationship between crude oil and the major asset classes. International Review of Economics and Finance, 33, 286-299.

Uri, N. D. (1996). Crude oil price volatility and unemployment in the United States. Energy, 21(1), 29-38.

Waheed, R., Wei, C., Sarwar, S., \& Lv, Y. (2018). Impact of oil prices on firm stock return: Industry-wise analysis. Empirical Economics, 55, 765-780.

Wang, L., Chang, H-L., Sari, A., Sowah, J. K., \& Cai, X-Y. (2020a). Resources or development first: An interesting question for a developing country. Resources Policy, 68, 101714.

Wang, L., Ma, F., Niu, T., \& He, C. (2020b). Crude oil and BRICS stock markets under extreme shocks: New evidence. Economic Modeling, 86, 54-68.

Xiao, D., \& Wang, J. (2020). Dynamic complexity and causality of crude oil and major stock markets. Energy, 193, 116791.

Youssef, M., \& Mokni, K. (2019). Do crude oil prices drive the relationship between stock markets of oil-importing and oil-exporting countries? Economies, 7(3), 70.

Youssef, M., Mokni, K. \& Ajmi, A. N. (2021). Dynamic connectedness between stock markets in the presence of the COVID-19 pandemic: Does economic policy uncertainty matter? Financial Innovation, $7,13,1-27$.

Zeileis A, Leisch F, Kleiber C, \& Hornik K. (2005). Monitoring Structural Change in Dynamic Econometric Models. Journal of Applied Econometrics, 20, 99-121.

Zhang, D., Hu, M., \& Ji, Q. (2020). Financial markets under the global pandemic of COVID-19. Finance Research Letters, 36, 101528.

Zhang, W., \& Hamori, S. (2021). Crude oil market and stock markets during the COVID-19 pandemic: Evidence from the US, Japan, and Germany. International Review of Financial Analysis, 74, 101702.

Zhu, H. M., Li, R., \& Li, S. (2014). Modelling dynamic dependence between crude oil prices and Asia-Pacific stock market returns. International Review of Economics \& Finance, 29, 208-223.

Zhu, H. M., Su, X., You, W., \& Ren, Y. (2016). Asymmetric effects of oil price shocks on stock returns: evidence from a two-stage Markov regime switching approach. Applied Economics, 47(25), 2491-2507. 